Boletim Científico do Instituto Agronômico do Estado de S. Paulo

Vol. 31

Campinas, agosto de 1972

N. ${ }^{\circ} 22$

\title{
EFEITO DA RETENÇÃO DE UM HERBICIDIA PELA COBERTURA MORTA DO SOLO, NO CONTROLE DAS ERVAS DANINHAS E NA PRODUÇÃO DO MILHO COM CULTIVO MINIMO ( $\left.{ }^{1}\right)$
}

F. I. Pastana, engenheiro-agrônomo, Seção de Conservação do Solo, Instituto Agronômico

\section{SINOPSE}

O presente trabalho foi planejado para determinar os efeitos da atrazina (AAtrex W-80), da cobertura morta com restos de cultura e da irrigação no crescimento das ervas daninhas e na produção do milho sob condições de solo semelhantes àquelas encontradas em cultivo mínimo.

Este estudo consistiu de dois experimentos de campo em duas séries de solo, Cecil e Norfolk, localizadas no Estado de Georgia, Estados Unidos da América. Áreas nos dois solos foram plantadas com milho e sem irrigação suplementar; e com solo coberto por palha de aveia ou simplesmente sem essa cobertura. Esses canteiros foram pulverizados com três doses de atrazina, com exceção dos tratamentos testemunhas.

Para as condições deste estudo, foram obtidas as seguintes conclusões: No solo série Cecil, o crescimento das ervas daninhas foi mais vigoroso nos canteiros sem irrigação e com a cobertura com palha do que nos canteiros com os outros tratamentos. Não houve diferença significativa no crescimento do mato entre tratamentos no solo série Norfolk. Observou-se nos dois experimentos que o crescimento das ervas tendia a ser menor à medida que as doses de atrazina aumentavam. No solo série Cecil, as produções de milho foram bem mais elevadas nos canteiros com cobertura de palha do que naqueles sem a cobertura, principalmente quando irrigados. A cobertura de palha não afetou significativamente as produções do milho no solo série Norfolk. A atrazina controlou as plantas invasoras e aumentou significativamente as produções de milho somente no solo série Norfolk.

\section{1 - INTRODUÇÃO}

Considerável número de trabalhos foi feito em instituições estrangeiras nos últimos vinte anos para desenvolver métodos adequados de preparo do solo e cultivo para o milho. O interesse

(1) Trabalho realizado com auxílio financeiro do Conselho Nacional de Pesquisas, para obtenção do grau de Master of Science. Recebido para publicação em 26 de novembro de 1971. 
por essa questão cresceu devido ao cuidado com relação à desagregação do solo, à redução da produção e aos elevados custos de preparo do solo por métodos convencionais.

Os trabalhos de investigação com o cultivo mínimo evoluíram da necessidade de desenvolver métodos que reduzissem os custos e evitassem efeitos prejudiciais ao solo, sem diminuir as produções da cultura. $\mathrm{O}$ cultivo mínimo consiste em preparar o solo com equipamento especial que não incorpora os restos da cultura anterior, deixando-os à superfície como uma cobertura protetora para reduzir a energia do impacto das gotas de chuva. A concorrência à água e aos nutrientes por intenso crescimento de ervas sob condições reduzidas de cultivo é um sério limite ao emprego de cultivo mínimo e ao seu valor potencial como processo de proteção do solo.

O aperfeiçoamento dos herbicidas estimulou sensivelmente, nesses países, o emprego do cultivo mínimo na produção do milho. Apesar desse impulso, muitas investigações com herbicidas em culturas diversas sugeriram que estes produtos químicos podem ter sua eficiência diminuída quando usados em cultivo mínimo. Esta redução da eficiência da ação tóxica no controle das ervas más possivelmente pode ser atribuída à interceptação das pulverizações de herbicidas pela cobertura superficial, a qual pode reter parte do princípio químico ativo e torná-lo, assim, menos efetivo em sua ação.

O objetivo deste trabalho foi pesquisar o efeito de uma cobertura de palha na retenção de um herbicida e essa influência sobre o crescimento das plantas invasoras e sobre a produção do milho.

\section{2 - REVISÃO DE LITERATURA}

O cultivo mínimo (minimum tillage) foi demonstrado, por vários pesquisadores nos Estados Unidos, ser um processo eficiente para conservar o solo.

Ensaios em Clemson (7), South Carolina, em 1939, provaram concludentemente que os resíduos de culturas, aplicados à superfície de solos da região Piedmont, foram muito mais eficientes na redução da enxurrada e das perdas de solo do que quantidades iguais do mesmo material incorporadas ao solo.

Efeitos benéficos de coberturas mortas com restos de culturas 
na estrutura do solo, na temperatura, umidade e aeração foram relatadas por Schaller (12), em trabalhos com milho, em canteiros tratados com 2,4-D e duas capinas. $\mathrm{O}$ autor informa que as contagens das plantas foram frequientemente mais baixas e apresentaram uma população mais elevada de ervas daninhas quando o solo recebeu uma aração reduzida e com cobertura do que quando recebeu aração comum.

Talbert e Fletchall (13), trabalhando em condições de estufa para testar métodos a fim de determinar a extensão da adsorção de cinco herbicidas radiativos pelos componentes do solo, concluíram que os materiais de natureza orgânica foram muito mais adsorventes do que as argilas.

Pesquisas feitas por Doherty e Warren (4), nas quais foram usados diferentes plantas e tipos de materiais orgânicos, demonstraram que a adsorção de um herbicida pelos colóides do solo pode torná-lo inaproveitável pelas ervas daninhas, e assim diminuir sua eficiência.

Buchholtz e Doersh (3) estudaram os efeitos de tratos culturais e aspersões de triazinas em cobertura total para o controle de ervas daninhas em milho, em diferentes regiões. Esses autores informaram que o crescimento do mato foi reduzido progressivamente pelas doses mais altas do herbicida aplicado em canteiros sem tratos culturais, sem contudo causar decréscimos consideráveis nas produções do milho.

Ensaios e uso de herbicidas para controlar ervas daninhas $\mathrm{em}$ viveiros de plantas ornamentais, taludes de vias de transporte, paisagismo etc. foram iniciados recentemente. Bing (1) testou a eficiência de um herbicida e combinações de diferentes materiais de cobertura morta em linhas de plantio em viveiros de plantas ornamentais; o autor, porém, não divulgou qualquer resultado específico relativo à retenção do herbicida pelas coberturas mortas empregadas em seu estudo.

Lamphear (9) também estudou esse problema, observando o efeito da incorporação de herbicidas a vários materiais de natureza orgânica usados como cobertura morta. Concluiu que esta técnica proporcionou controle de ervas igual ou melhor que o herbicida ou a cobertura empregados separadamente.

Robocker e Canode (11), trabalhando em condições de labo- 
ratório com três herbicidas seletivos em sementeira de uma gramínea (Downy bromegrass) aplicados a materiais orgânicos, informou que a interceptação pela palha de cobertura foi tida como o fator mais importante na redução da eficiência da ação dos herbicidas.

Haramaki e colaboradores (8), usando uma cobertura composta de casca de carvalho desintegrada e doisł herbicidas, constataram uma eficiência melhorada da ação do herbicida quando estes foram pulverizados no material de cobertura antes de sua aplicação. Esses pesquisadores também informaram que, em geral, quando a concentração do herbicida, a espessura da cobertura ou a combinação de ambas as coisas é aumentada, o controle das ervas é mais eficiente; nenhuma referência foi feita à possível causa deste efeito.

Estudos semelhantes foram conduzidos por Fretz e colaboradores (7), Dunham e colaboradores (5), Dunham e Fretz (6) e Big e Fasser (2).

Estes autores, trabalhando em diferentes localidades, com várias culturas sob diversas condições, utilizando variados tipos de materiais de cobertura, obtiveram resultados contraditórios, quanto ao efeito dessas coberturas na eficiência da ação do herbicida empregado.

Concluiu-se dos experimentos anteriores, relatados pelos mencionados pesquisadores, ser necessária uma pesquisa complementar envolvendo o assunto sob condições de campo para poder avaliar melhor os efeitos de um material de palha, usado como cobertura, na eficiência do herbicida, e sua influência sobre a produção da cultura.

\section{3 - MATERIAIS E METODOS}

Experimentos de campo foram conduzidos em duas séries de solos para estudar os efeitos da retenção do herbicida pela cobertura morta. Estes solos são, segundo a $7 .^{a}$ Aproximação $\left({ }^{2}\right)$, um hapludult típico da série Cecil e um paleudult típico da série Norfolk, localizados, respectivamente, em Watkinsville e Midville, Estado da Georgia. As características físicas da camada arável

\footnotetext{
$\left(^{2}\right)$ Soil Survey Staff. Supplement to soil classification System. (7th Approximation) U.S. Department of Agriculture, March, 1967.
} 
$(0-20 \mathrm{~cm})$ desses solos são relacionados a seguir.

Cecil

Textura

Estrutura

Consistência

Cor barro-arenosa

granular muito

fina e fraca

friável

bruno-amarelado

(10 YR 5/3)
Norfolk areno-barrenta granular fina e fraca muito friável cinza $(10$ YR3/1)

Os experimentos consistiram de canteiros secundários, com e sem irrigação suplementar, plantados com milho, e subdivididos em canteiros com e sem cobertura morta, tratados com quatro níveis de um herbicida.

A área experimental foi preparada previamente por métodos convencionais. Uma cobertura de palha de aveia a uma razão equivalente a $2500 \mathrm{~kg} / \mathrm{ha}$ foi aplicada a mão, após o plantio dos canteiros que teriam cobertura. AAtrex W-80 (atrazina) foi pulverizado em cada canteiro tratado com herbicida. Estes tratamentos consistiram de quatro diferentes níveis de aplicação, a saber: - 1) sem herbicida, 2) dose normal, 3) duas vezes a dose normal, 4) três vezes a dose normal de aplicação recomendada para cada tipo de solo em particular. As doses de herbicida para cada localidade foram: sem herbicida (Ho), 4,0 kg/ha (dose normal), 8,0 kg/ha e $12,0 \mathrm{~kg} / \mathrm{ha}$ para a série Cecil e sem herbicida (Ho), 2,2 kg/ha (dose normal), $4,4 \mathrm{~kg} / \mathrm{ha}$ e $6,6 \mathrm{~kg} / \mathrm{ha}$ para a série Norfolk.

Irrigação suplementar por aspersão garantiu o desenvolvimento do milho durante os períodos de seca. As flutuações na umidade disponível do solo foram acompanhadas por meio de leituras da resistência de blocos de Boyoucos instalados na área irrigada. delineamento experimental foi o de blocos completamente casualizados, tendo irrigação como tratamento de interesse secundário, e os de cobertura como subparcela e as doses de aplicação de herbicida como sub-subparcela. As dimensões dos canteiros foram de $3,9 \mathrm{~m}$ por $6,1 \mathrm{~m}$, com quatro linhas de milho distantes $0,96 \mathrm{~m}$ entre si. Não foi utilizado cultivo mecânico para controlar as ervas daninhas. Irrigação suplementar foi necessária seis vezes em ambas as localidades, durante a época de crescimento. As ervas daninhas foram coletadas de área de $0,96 \mathrm{~m}$ por $3,05 \mathrm{~m}$, situada entre as duas linhas centrais de milho. $\mathrm{O}$ milho foi colhido de uma área 
de $0,96 \mathrm{~m}$ por $4,50 \mathrm{~m}$, e a produção de grãos calculada a partir do peso seco obtido em secadores.

\section{4 - RESUlTADOS E CONCLUSÕES}

\section{1 - SÉRIE CECIL}

Os canteiros irrigados tiveram significativamente menos ervas do que os não irrigados. Esse efeito foi provavelmente o resultado de melhores condições para a solubilidade de atrazina, que ficou disponível em maior quantidade no solo para a absorção pelas ervas.

Além do irrigado, os tratamentos com cobertura apresentaram maior crescimento de ervas do que os sem cobertura. Isso, aparentemente, foi devido à remoção parcial da atrazina da palha pela irrigação e pela chuva.

A interação irrigada $\mathrm{x}$ cobertura apresentou menos ervas onde as condições vieram também favorecer a lavagem da atrazina da palha, tal como aconteceu nos canteiros irrigados e com cobertura, que apresentavam menor quantidade de ervas do que os não irrigados e com cobertura. As chuvas, que foram irregularmente distribuídas na época do crescimento, em 1970 (quadro 7), na região do solo da série Cecil, possivelmente contribuiram para lavar quantidades reduzidas de atrazina da palha, onde esta permaneceu sem efeito.

$\mathrm{O}$ crescimento das ervas diminuiu nos canteiros tratados com diferentes doses de atrazina. A infestação de ervas foi avaliada pelo peso da matéria seca, e é apresentada no quadro 2.

Todos os efeitos de interações de tratamentos foram também efetivos na redução do crescimento das ervas. Para todas as doses de atrazina esse crescimento foi menos severo nos tratamentos irrigados do que nos não irrigados. Contrariamente, todas as doses do herbicida foram menos efetivas em reduzir o crescimento das ervas nos tratamentos com cobertura, comparativamente aos sem cobertura. Isto sugeriu que pode ter ocorrido retenção parcial pela palha de cobertura, possivelmente devido à lavagem insuficiente da palha nos canteiros não irrigados quando comparados com as mesmas doses aplicadas a canteiros não irrigados e com cobertura, que 
foram os que apresentaram mais ervas.

As diferenças em infestação entre os efeitos das interações antes mencionadas foram altamente significativas e indicaram que a água de irrigação e/ou da chuva podem ter lavado a atrazina da palha, escorrendo-a para o solo, onde ela permaneceu ativa.

Os rendimentos do milho aumentaram consideravelmente com

Quadro 1. - Efeitos de aplicações de herbicida, de irrigação e de cober-

tura morta no solo, sobre o peso seco de ervas invasoras em solo da série Cecil cultivado com milho na Georgia, EUA

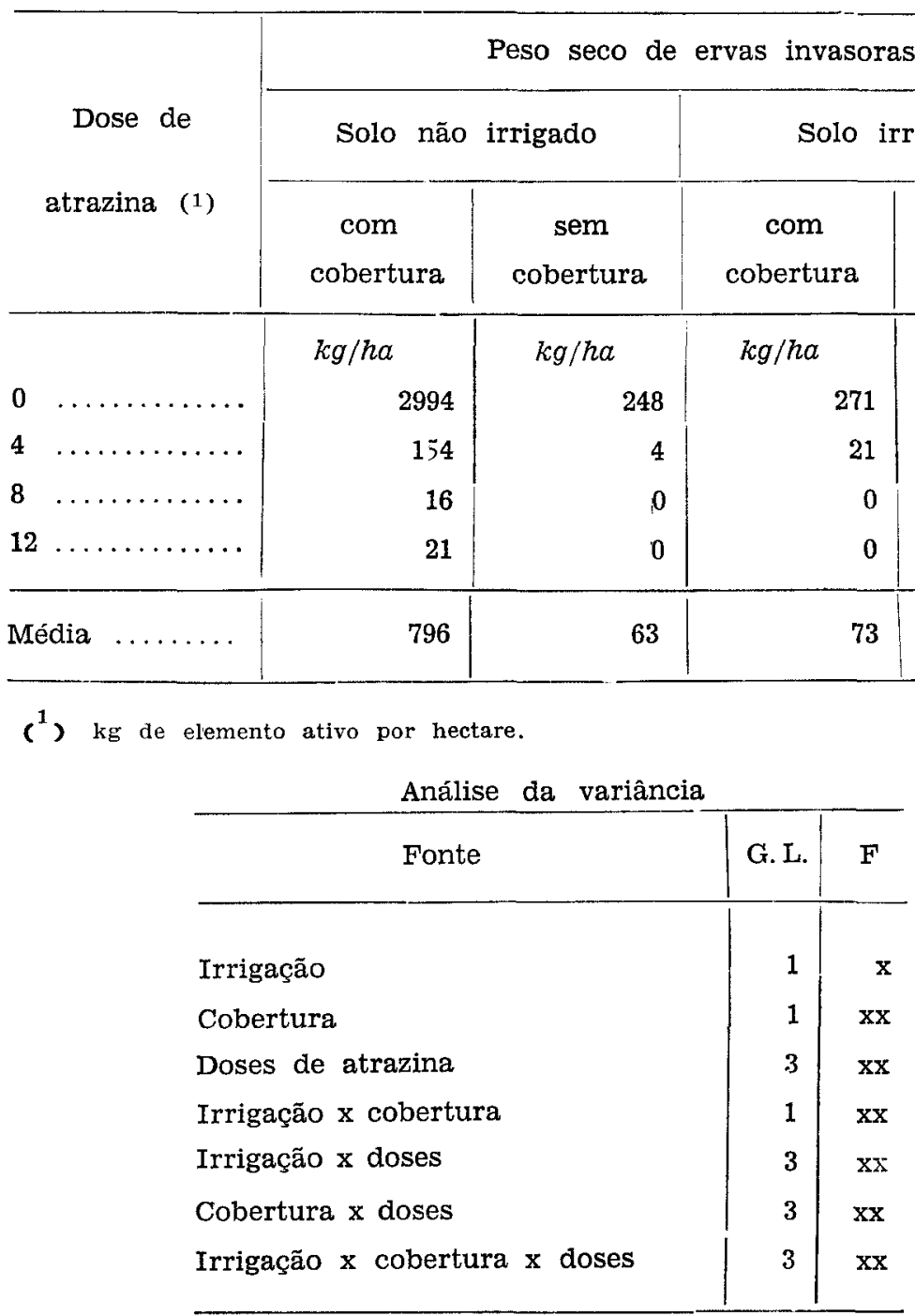




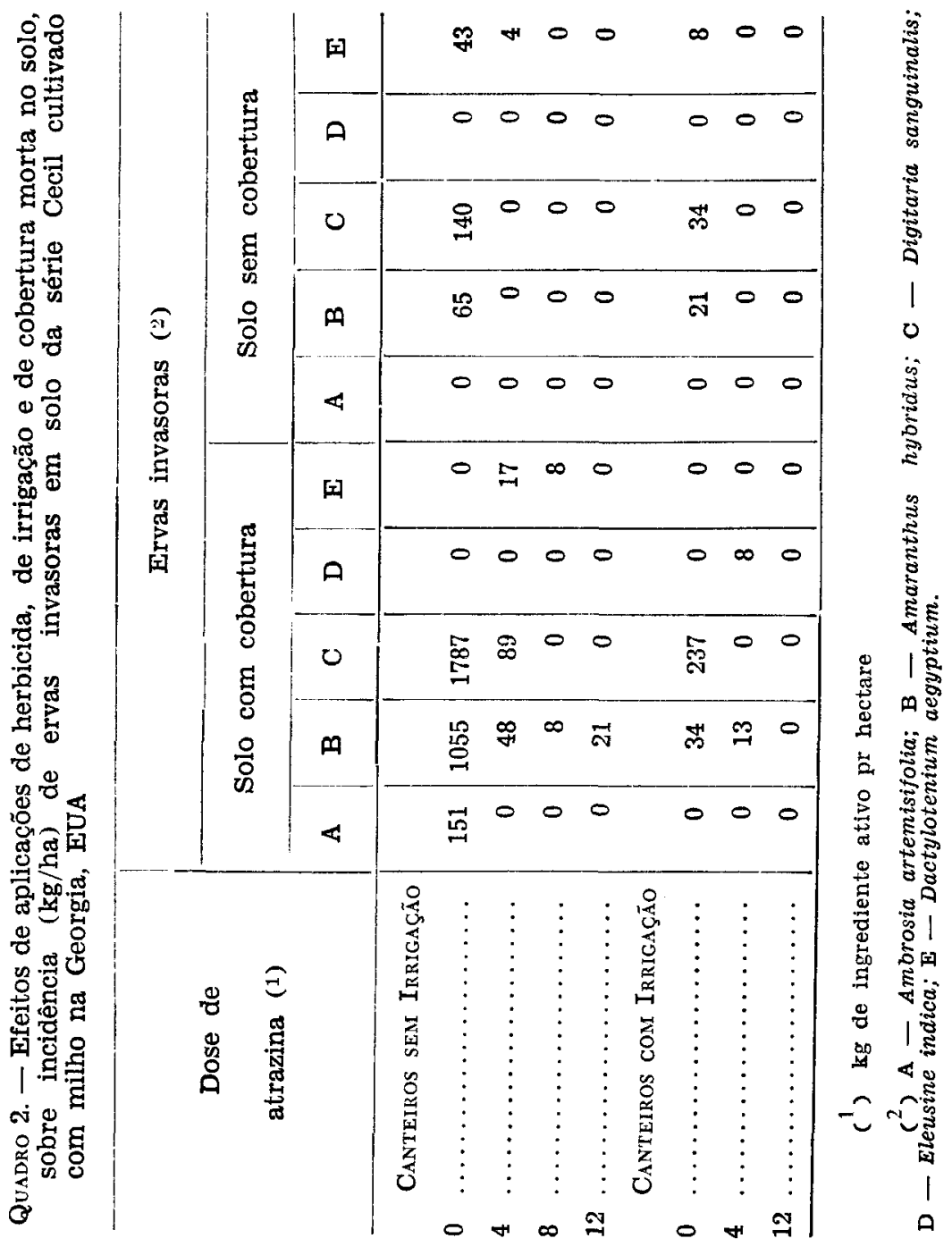


a irrigação, assim novamente demonstrando a importância da irrigação suplementar na produção dessa cultura na Georgia. Da mesma forma, o milho produziu mais com cobertura. A interação irrigação $\mathrm{x}$ cobertura demonstrou que os rendimentos do milho foram mais elevados nos tratamentos com irrigação e com cobertura.

Quadro 3. - Efeitos de aplicações de herbicida, de irrigação e de cobertura morta no solo, sobre a produção de milho cultivado em solo da série Cecil, na Georgia, EUA

\begin{tabular}{|c|c|c|c|c|}
\hline \multirow{3}{*}{$\begin{array}{c}\text { Dose de } \\
\text { atrazina (1) }\end{array}$} & \multicolumn{4}{|c|}{ Peso seco de milho } \\
\hline & \multicolumn{2}{|c|}{ Solo sem irrigação } & \multicolumn{2}{|c|}{ Solo com irrigação } \\
\hline & $\begin{array}{c}\text { com } \\
\text { cobertura }\end{array}$ & $\begin{array}{c}\text { sem } \\
\text { cobertura }\end{array}$ & $\begin{array}{c}\text { com } \\
\text { cobertura }\end{array}$ & $\begin{array}{c}\text { sem } \\
\text { cobertura }\end{array}$ \\
\hline & $k g / h a$ & $k g / h a$ & $k g / h a$ & $k g / h a$ \\
\hline$\ldots \ldots \ldots \ldots$ & 1384 & 1763 & 7740 & 4545 \\
\hline 4 & 1560 & 1101 & 7091 & 3806 \\
\hline .. & 2186 & 778 & 7798 & 4161 \\
\hline $12 \ldots$ & 1730 & 1323 & 8254 & 3806 \\
\hline Média & 1715 & 1241 & 7721 & 4080 \\
\hline
\end{tabular}

(') $\mathrm{kg}$ de ingrediente ativo por hectare.

Análise da variância

\begin{tabular}{l|r|r}
\hline \multicolumn{1}{c|}{ Fonte } & G. L. & F \\
\hline Irrigação & 1 & $\mathrm{xx}$ \\
Cobertura & 1 & $\mathrm{xx}$ \\
Doses de atrazina & 3 & $\mathrm{n} . \mathrm{s.}$ \\
Irrigação x cobertura & 1 & $\mathrm{xx}$ \\
Irrigação x doses & 3 & n.s. \\
Cobertura x doses & 3 & n.s. \\
Irrigação x cobertura x doses & 3 & n.s. \\
& & \\
\hline
\end{tabular}


As produções mencionadas foram todas significativamente diferentes, e são apresentadas no quadro 3. Produções de milho e infestação de ervas tiveram relação inversa estreita.

\section{2 - SÉRIE NORFOLK}

A irrigação não afetou significativamente o crescimento das ervas daninhas, nesta série, embora, em média, a infestação tivesse sido menor nos canteiros com cobertura.

Os efeitos da cobertura de palha no crescimento das ervas foram não significativos porque a infestação nos tratamentos com e sem cobertura foi comparável. A retenção de atrazina pela palha deve ter sido reduzida pelas aspersões e pela chuva. A distribuição da chuva parece ter sido importante na eliminação da atrazina da palha nos tratamentos não irrigados, porque não foi suficiente para causar uma lavagem extensa.

Verificou-se que o crescimento das ervas variou muito quanto às doses de herbicidas. As diferenças observadas entre essas doses foram altamente significativas. Este efeito resultou provavelmente das concentrações de atrazina disponíveis no solo para a absorção pelas ervas. A variação observada foi provavelmente causada por uma infestação inicial irregular de ervas na área do ensaio e não pelo efeito de tratamento. Dados e análise da variância relativos ao crescimento das ervas são apresentados no quadro 4.

A interação dos tratamentos não causou diferenças de vulto no crescimento das ervas. Este fato pode ser explicado pela atividade da atrazina no solo em todos os tratamentos, em quantidades suficientes para produzir toxidez às ervas. Espécies de ervas daninhas encontradas no local são apresentadas no quadro 5 .

As variaçōes em crescimento das ervas relacionadas com as doses foram, provavelmente, causadas por infestações localizadas e não por efeito desses tratamentos.

As produções de milho nāo foram afetadas pela irrigação ou pela cobertura. Diferenças aparentes entre tratamentos com e sem irrigação bem como entre os tratamentos com e sem cobertura com palha foram nāo significativas. Entretanto, houve diferenças significativas em produções de milho para as doses de atrazina. Este fato indicou uma extensão de atividade diferente para cada dose no solo após sua lavagem pela água. Os efeitos de interação para 
Quadro 4. - Efeitos de aplicações de herbicida, de irrigação e de cobertura morta no solo, sobre o peso seco de ervas invasoras em solo da série Norfolk cultivado com milho na Georgia, EUA

\begin{tabular}{|c|c|c|c|c|}
\hline \multirow{3}{*}{$\begin{array}{c}\text { Dose de } \\
\text { atrazina }(1)\end{array}$} & \multicolumn{4}{|c|}{ Peso seco das ervas daninhas } \\
\hline & \multicolumn{2}{|c|}{ Solo sem irrigação } & \multicolumn{2}{|c|}{ Solo com irrigação } \\
\hline & $\begin{array}{c}\text { com } \\
\text { cobertura }\end{array}$ & $\begin{array}{c}\text { sem } \\
\text { cobertura }\end{array}$ & $\begin{array}{c}\text { com } \\
\text { cobertura }\end{array}$ & $\begin{array}{c}\text { sem } \\
\text { cobertura }\end{array}$ \\
\hline & $\mathrm{kg} / \mathrm{ha}$ & $k g / h a$ & $\mathrm{~kg} / \mathrm{ha}$ & $k g / h a$ \\
\hline 0 & 2533 & 3675 & 3121 & 5363 \\
\hline 2,2 & 3111 & 477 & 908 & 1151 \\
\hline 4,4 & 811 & 601 & 192 & 38 \\
\hline 6,6 & 10 & 364 & 0 & 4 \\
\hline Média & 1616 & 1279 & 1055 & 1639 \\
\hline
\end{tabular}

(1) $\mathrm{kg}$ de ingrediente ativo por hectare.

Análise da variância

\begin{tabular}{l|r|r}
\hline \multicolumn{1}{c|}{ Fonte } & G. L. & F \\
\hline Irrigação & 1 & n.s. \\
Cobertura & 1 & n.s. \\
Doses de atrazina & 3 & xx \\
Irrigação x cobertura & 1 & n.s. \\
Irrigação x doses & 3 & n.s. \\
Cobertura x doses & 3 & n.s. \\
Irrigação x cobertura x doses & 3 & n.s. \\
& & \\
\end{tabular}




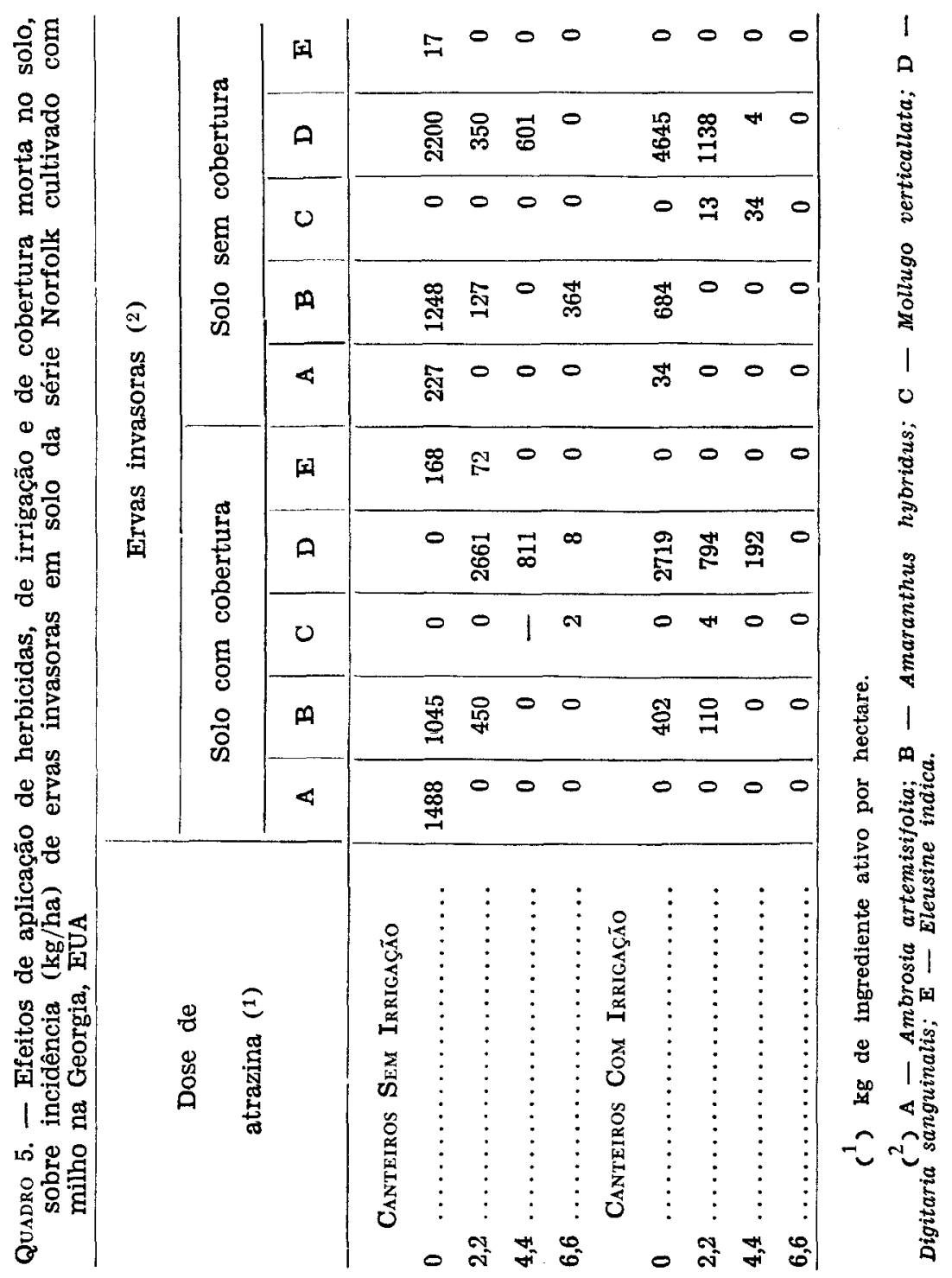


todos esses tratamentos foram não significativos. Os dados e a análise da variância relativos à produção do milho são apresentados no quadro 6.

Qundro 6. - Efeitos de aplicações de herbicida, de irrigação e de cobertura morta no solo, sobre a produção de milho cultivado em solo da série Norfolk, na Georgia, EUA

\begin{tabular}{|c|c|c|c|c|}
\hline \multirow{3}{*}{$\begin{array}{c}\text { Dose de } \\
\text { atrazina (1) }\end{array}$} & \multicolumn{4}{|c|}{ Peso seco do milho } \\
\hline & \multicolumn{2}{|c|}{ Solo sem irrigação } & \multicolumn{2}{|c|}{ Solo com irrigação } \\
\hline & $\begin{array}{c}\text { com } \\
\text { cobertura }\end{array}$ & $\begin{array}{c}\text { sem } \\
\text { cobertura }\end{array}$ & $\begin{array}{c}\text { com } \\
\text { cobertura }\end{array}$ & $\begin{array}{c}\text { sem } \\
\text { cobertura }\end{array}$ \\
\hline & $k g / h a$ & $k g / h a$ & $\mathrm{~kg} / \mathrm{ha}$ & $k g / h a$ \\
\hline$\cdots$ & 3511 & 1811 & 2203 & 2438 \\
\hline 2,2 & 2692 & 4247 & 3907 & 4552 \\
\hline 4,4 & 4995 & 3472 & 4328 & 3970 \\
\hline 6,6 & 4464 & 4595 & 4630 & 4630 \\
\hline Média .... & 3915 & 3531 & 3767 & 3822 \\
\hline
\end{tabular}

( $\left.{ }^{1}\right) \mathrm{kg}$ de ingrediente ativo por hectare.

Análise da variância

\begin{tabular}{l|r|r}
\multicolumn{1}{c|}{ Fonte } & G.L. & F \\
\hline & 1 & n.s. \\
Irrigação & 1 & n.s. \\
Cobertura & 3 & $\mathrm{x}$ \\
Doses de atrazina & 1 & n.s. \\
Irrigação x cobertura & 3 & n.s. \\
Irrigação x doses & 3 & n.s. \\
Cobertura x doses & 3 & n.s. \\
Irrigação x cobertura x doses & & \\
\hline
\end{tabular}


Quadro 7. - Dados pluviométricos diários de Watkinsville e Midville, Georgia, EUA, durante os meses de maio, junho e julho de 1970 (1)

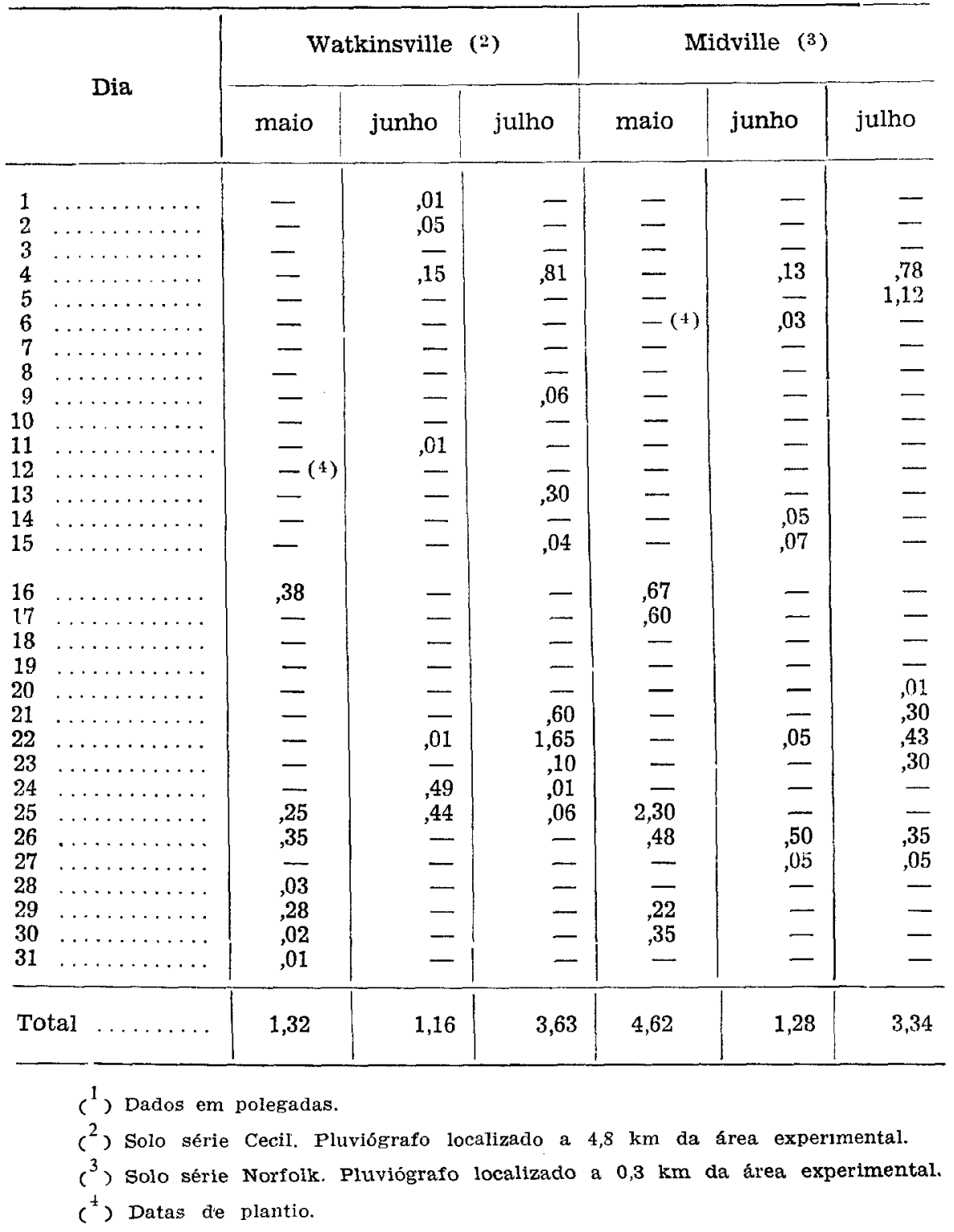




\section{EFFECTS OF HERBICIDE, MULCHING, AND IRRIGATION ON WEED GROWTH AND CORN YIELD}

\section{SUMMARY}

This study was designed to determine the effects of atrazine, mulching, and irrigation on weed growth and corn yields in minimum tillage. It consisted of two field experiments set out on two soil types, which were a Typic Hapludult, Cecil series, and a Typic Paleudult, Norfolk series, 10cated at Watkinsville and Midville, Georgia, U.S.A., respectively. The experimental areas were planted to corn with irrigated and non-irrigated treatments, with mulched and non-mulched (bare) soil surfaces. These plots were sprayed with four rates of atrazine (AAtrex W-80).

For the conditions of this study, the following conclusions are indicated: 1 - weed growth was more vigorous on mulched, non-irrigated plots than on plots with other treatments on Cecil soil. No significant differences in weed growth were found between treatments on Norfolk soil. On both experiments it was observed that weed growth tended to be less as rates of atrazine were increased; 2 - corn yields were substantially higher on mulched soil than under non-mulched ones, especially with irrigation on Cecil soil. Mulching did not affect corn yields significantly on the Norfolk soil. Atrazine controlled weeds and increased corn yields significantly on the Norfolk soil only.

\section{LITERATURA CITADA}

1. BING, A. The use of herbicide with mulch. Proc. of the Northeastern Weed Control Conf. 19:167-172, 1965.

2. \& FASSER, D. Weed control in highway plantings. Proc. of the Northeastern Weed Control Conf. 24:55-60, 1970.

3. BUCHHOLTZ, K. P. \& DOERSH, R. E. Cultivation and herbicides for weed control in corn. Weeds 16:232-234, 1968.

4. DOHERTY, P. J. \& WARREN, G. F. The adsorption of four herbicides by different types of organic matter and a bentonite clay. Weed Res. 9:20-26, 1969.

5. DUNHAN, C. W.; RAHN, E. M. \& FRETZ, T. A. Use of mulch incorporated herbicides for control of weeds in new ground cover plantings. Proc. of Northeastern Weed Control Conf. 21:190-195, 1967.

6. — FRETZ, T. A. Licorice root-dichlobenil mulch combination for control of weeds in boxwood plantings. Proc. west. Weed Control Conf., 22:255-257, 1968.

7. FRETZ, T. A.; DUNHAN, C. W. \& RAHN, E. M. The incorporation of herbicides in organic mulchs for use on ornamental plantings. Proc. of the Northeastern Weed Control Conf. 20: 204-208, 1968.

8. HARAMAKI, C.; NUSS, J. R. \& WILLIAMS, P. H. Herbicides incorporated hardwood bark mulch for ornamentals. Proc. of the Northeastern Weed Control Conf. 23:76-80, 1969.

9. LAMPHEAR, F. D. Incorporation of dichlobenil in mulches. Weeds 16:230-231, 1968 .

10. PEELE, T. C.; NUTT, G. B. \& BEALE, O. W. Utilization of plant residues as mulches in the production of corn and cats. Proc. Soil Sci. Soc. Am., 11:356-360, 1946. 
11. ROBOCKER, W. C. \& CANODE, C. I. Effects of litter, incorporated organic matter, soil type and selective herbicide on seedlings of Downy brome. Weeds 13:8-10, 1965.

12. SCHALLER, F. D. \& EVANS, D. D. Some effects of mulch tillage. Agr. Eng. 35:731-733, 1954.

13. TALBERT, R. E. \& FLETCHALL, O. H. The organic adsorption of some S-triazine in soils. Weeds 13:46-15, 1965. 